\title{
BIM PARA GESTÃO DE RESÍDUOS NA CONSTRUÇÃO CIVIL
}

\section{VERÔNICA MARTINS GNECCO | UFSC LETICIA MATTANA, M.SC. |UFSC}

\section{INTRODUÇÃO}

A indústria da construção civil destaca-se como um dos setores que mais gera resíduos. Porém, possui grande representatividade na economia do país e reflete diretamente a situação econômica e social que o mesmo se encontra. Apesar disso, ao comparar o setor com outras áreas, percebemos o quanto ainda é atrasado em questão de tecnologia. Assim, a gestão e redução dos resíduos no setor da construção civil não são adequados. O processo BIM surge como alternativa para facilitar a resolução destes problemas. Neste trabalho foram estudadas as possibilidades oferecidas pelo BIM para a gestão de resíduos, utilizando-se de um estudo de caso para fins práticos e comparativos: a obra do CRAS de Biguaçu/SC. Para o estudo, foram (a) investigadas as principais ferramentas BIM que contribuem para a gestão de resíduos, (b) analisado o caso de estudo para cada alternativa oferecida pelo BIM para redução ou controle da gestão de resíduos, (c) levantamento in loco de quantitativos de alvenaria do caso de estudo e estudo comparativo com o modelo BIM, (d) elaboração e aplicação de entrevistas com os envolvidos na obra e na modelagem desta edificação e (e) análise dos resultados e considerações finais. O processo BIM apresenta grande capacidade de análise, compilação, organização e registro de informações para a gestão de resíduos, ainda subutilizados na construção civil brasileira, principalmente na etapa de execução de obras. Destaca-se também a importância da colaboração entre as equipes envolvidas, para o sucesso da gestão de resíduos através do processo BIM. Pelos resultados obtidos, infere-se que o BIM na gestão de resíduos deve ser melhor estudado e aplicado pelas empresas responsáveis pelos projetos de arquitetura e engenharia, evitando obras custosas financeira e ambientalmente.

\section{OBJETIVOS}

O objetivo geral do estudo é a investigação de como o processo BIM pode contribuir para gestão de resíduos de uma edificação.

Além disso, o estudo apresenta como objetivos específicos: (a) conhecer as ferramentas BIM e as suas potencialidades na gestão de resíduos, (b) verificar como ocorre a interação entre o modelo BIM e o canteiro de obras e (c) Propor alternativas para a redução dos resíduos no canteiro de obras, usando o BIM.

\section{RESULTADOS}

Através da revisão bibliográfica realizada, foram identificados quais softwares BIM auxiliam nas fases de projeto e gestão dos resíduos. Segundo Deshpande e Whitman (2014) o AUTODESK REVIT apresenta funcionalidades que permitem prever virtualmente a utilização espacial do canteiro de obras e o AUTODESK NAVISWORKS auxilia nas simulações temporais do processo construtivo. Outras fases de projeto apresentam influência nos resíduos de construção e demolição, tendo também softwares que contribuem para a eficácia da execução da etapa. Alguns desses foram expostos no trabalho de Won e Cheng (2017), utilizado como base para a pesquisa.

No estudo de caso do presente trabalho, o CRAS de Biguaçu, os softwares utilizados que colaboraram para a gestão dos resíduos foram (1) revisão e compatibilização de projetos através do uso das ferramentas NEMESTSCHEK SOLIBRI MODEL CHECKER e TEKLA BIM SIGHT, (2) no planejamento do canteiro de obras através do uso da ferramenta GRAPHISOFT ARCHICAD, (3) no projeto dos sistemas de construção através do uso das ferramentas GRAPHISOFT ARCHICAD, ALTOQI EBERICK e ALTOQI QIBUILDER e (4) no controle e planejamento 3D através do uso da ferramenta GRAPHISOFT ARCHICAD.

Nas visitas ao canteiro de obras foi constatado o constante desperdício de material e ausência de planejamento na execução da obra, com o uso do BIM apenas na fase 
de projeto. O processo de execução era bastante artesanal, sem variação por ser um projeto realizado através de ferramentas em BIM. Os materiais ficavam muitas vezes expostos às intempéries, evidenciando o pouco planejamento do canteiro de obras e falta de previsão para armazenagem e movimentação de materiais. As quebras de tijolo para inclusão de instalações e o desperdício de materiais no entorno da obra era evidente e prejudicava a movimentação dos trabalhadores e visitantes.

Por outro lado, o BIM foi aplicado em algumas situações com êxito para a redução dos resíduos, como na detecção de conflitos interferências e colisões que, segundo o responsável pela modelagem do CRAS, foi importante para o trabalho de maneira mais coordenada e sistêmica. Entretanto, nas visitas ao canteiro foram verificados conflitos com as instalações e os elementos estruturais, causados por erros de projeto ou pela interpretação errônea dos projetos, os quais foram disponibilizados apenas em PDF pela empresa executora. Outras utilidades do BIM que não foram utilizadas adequadamente no projeto em estudo foram o planejamento da construção, a sincronização do projeto e do layout do canteiro e a previsão da quantidade de material. Todas essas omissões tiveram impactos financeiros, ambientais e nos prazos do projeto.

Ainda, foi medida a alvenaria do empreendimento, primeiramente através do software BIM e depois em obra. Foi constatada que a alvenaria foi aproximadamente $1,07 \%$ menor em obra do que no software, portanto a metodologia para quantificação pode ser utilizada com certa exatidão, mas não considera os possíveis desperdícios de material que podem ocorrer na execução. Fazendo um comparativo com os dados de obra disponibilizados pelo engenheiro responsável pela execução, a diferença para o valor medido foi, em média, de 18,03\% menor que o valor comprado de tijolos de alvenaria.

\section{CONSIDERAÇÕES FINAIS}

Por meio das visitas feitas em obra, da análise feita no modelo BIM disponibilizado para estudo, das entrevistas realizadas com profissionais envolvidos no projeto e das pesquisas realizadas em bibliografias acadêmicas, concluiu-se que o CRAS de Biguaçu não utilizou adequadamente os recursos do processo BIM para a gestão de resíduos, principalmente no que diz respeito à gestão e execução da obra. A implantação da tecnologia é, ainda, muito recente para a maioria das empresas de projeto e execução, as quais ainda não têm conhecimento de todas as potencialidades dos processos e ferramentas.
Percebeu-se desarmonia entre as etapas do processo de projeto e gestão de obras nesta edificação, fator essencial para o sucesso do BIM no empreendimento.

Sugerem-se revisões constantes do projeto, com prioridade à colaboração e a melhoria dos processos, com maior cuidado nas etapas de gestão, construção e gerenciamento da obra.

\section{REFERÊNCIAS}

DESHPANDE, A.; WHITMAN, B.. Evaluation os the Use of BIM Tools for Construction Site. In: ASC ANNUAL INTERNATIONAL CONFERENCE, 50., 2014, Auburn. Proceddings. Auburn: Associated Schools Of Construction, 2014. p. 70 - 78.

WON, J.; CHENG, J. Identifying potential opportunities of building information modeling for construction and demolition waste management and minimization. Automation In Construction, Online, v. 79, p.3-18, jul. 2017. 